\title{
Role of 2,3-cis Structure of (-) -Epicatechin-3,5-O-digallate in Inhibition of HeLa S3 Cell Proliferation
}

Kazuki Mori', Yoshihiro Ayano¹, Yoshitomo Hamada1, Taichi Hojima1, Ryuta Tanaka1, Yusuke Higashino", Mayu Izuno', Taisuke Okamoto1,

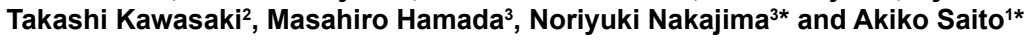

${ }^{1}$ Graduate School of Engineering, Osaka Electro-communication University (OECU), 18-8 Hatsu-cho, Neyagawa-shi, Osaka 572-8530, Japan

${ }^{2}$ Department of Pharmaceutical Sciences, Ritsumeikan University, 1-1-1 Nojihigashi, Kusatsu, Shiga 525-8577, Japan

${ }^{3}$ Biotechnology Research Center and Department of Biotechnology, Toyama Prefectural University, 5180 Kurokawa, Imizu, Toyama 939-0398, Japan

\begin{abstract}
Flavan-3-ol, which is primarily found in tea, is able to inhibit the proliferation of the human cancer cell line HeLa S3; in this study, we investigate the importance of the 2,3-cis structure in this inhibition. We synthesized six (-)-epicatechin and $(+)$-catechin analogs modified with a galloyl moiety at either the 3-hydroxyl, 5-hydroxyl, or 3,5-dihydroxyl positions. We then investigated their biological activity, DPPH radical scavenging activity and inhibitory activity on HeLa S3 cell proliferation. Among the six compounds, (-)-epicatechin-3,5-O-digallate showed the strongest inhibitory activity on HeLa S3 cell proliferation, whereas (+)-catechin-3,5-O-digallate was not active. In addition, there is no relation among the cell proliferation inhibitory activity and DPPH radical scavenging activity. Furthermore non-specific BSA binding ability of synthesized compounds was demonstrated. Improved photoaffinity beads method revealed that there is no difference between (-)-epicatechin-3,5-O-digallate and (+)-catechin-3,5-O-digallate on the non-specific BSA absorption. These data indicated that the 2,3-cis structure of flavan-3-ol is essential for the inhibition of HeLa S3 cell proliferation.
\end{abstract}

Keywords: Condensed tannins; Oligomeric flavonoid; Synthesis; Cancer cells proliferation; Inhibitory activity

\section{Abbreviations}

DPPH: 2,2-diphenyl-1-picrylhydrazyl; BSA: Bovine Serum Albumin;TBS: tert-butyldimethylsilyl;DCC: dicyclohexylcarbodiimide; TBAF: Tetra- $n$-butylammonium Fluoride; EDC: 1-ethyl-3(3-dimethylaminopropyl) carbodiimide hydrochloride; THF: Tetrahydrofuran;DMF: $N, N$-dimethylformamide; TFA:Trifluoroacetic Acid; DMAP: $N, N$-dimethyl-4-aminopyridine

\section{Introduction}

There is currently great interest in the investigation of compounds from food sources that have strong biological activities; as these compounds are generally considered highly safe if they are already part of the diet. Polyphenols are thought to have various health benefits; and as such; are found in many health foods; as well as vegetables and fruits $[1,2]$. Furthermore; the investigation of polyphenol compounds is now increasingly important because of their various beneficial biological activities. However; the Structure-Activity Relationship (SAR) of polyphenols is not well understood because they are obtained as a mixture of various analogs in many cases; which makes purification difficult. Therefore; we have developed a simple; versatile; stereoselective and length-controlled synthetic method for various polyphenols containing with (-)-epicatechin (1) and (+)-catechin (2) analogs (Figure 1). We have also demonstrated that the galloyl modification of the hydroxyl groups of flavan-3-ols can enhance their biological activity [3-6].

Binding of polyphenols with proteins is often adopted for determination of the concentration of polyphenols to evaluate astringency of food products [7]; based on non-specific protein binding of polyphenols. This non-specific protein binding is commonly considered to be one of the factors of poor-bioavailability of polyphenol compounds $[8,9]$. Considerable research; however; indicates that the interactions to proteins are not so non-specific recently. Therefore we are interested in the non-specific binding of our polyphenol compounds to proteins such as serum albumin. Especially; BSA (bovine serum albumin) is abundant as the constituent of the culture medium in the assays using mammalian cells.
Here; we describe the development of a regioselective deprotection of tert-butyldimethylsilyl (TBS) protected flavan-3-ols; allowing for modification of the 5-position with various moieties; such as the galloyl group and the SAR studies of 3- or 5-O-galloyl-modified $(-)$-epicatechin (1) and (+)-catechin (2); as well as the DPPH radical scavenging and inhibitory activities toward HeLa S3 cell proliferation. We also investigated the nonspecific protein binding with synthesized polyphenols using improved photoaffinity beads.

\section{Materials and Methods}

\section{General}

All commercially available chemicals were used without further purification. All reactions were performed under an argon atmosphere and monitored using thin-layer chromatography (TLC) with $0.25 \mathrm{~mm}$ pre coated silica-gel plates (Merck 60F254 Art 5715). An ATAGO AP300 spectrometer was used to measure optical rotation. ${ }^{1} \mathrm{H}-\mathrm{NMR}$ spectra were recorded on an Agilent Inova 500 Spectrometer $(500 \mathrm{MHz})$ and an Agilent DD2 NMR Spectrometer (400 MHz). A JEOL JMS-AX500 mass spectrometer was used to acquire fast atom bombardment (FAB) mass spectra. A Bruker Daltonics micrOTOF focus mass spectrometer was used to acquire electrospray ionization (ESI). The human cervical adenocarcinoma cell line; HeLa S3; were provided by the RIKEN BRC through the National Bio-Resource Project of the MEXT; Tsukuba; Japan. Synthesized compounds were dissolved in dimethyl sulfoxide

*Corresponding author: Raveendran VV, Associate Scientist, Cardiovascular Research Program, King Faisal Specialist Hospital and Research Center, Riyadh, 11211, Saudi Arabia, Tel: +966 500973 072; E-mail: vrvineesh@gmail.com

Noriyuki Nakajima, Biotechnology Research Center and Department of Biotechnology, Toyama Prefectural University, 5180 Kurokawa, Imizu, Toyama 939-0398, Japan, Tel: 81-766-56-2498, E-mail: nori@pu-toyama.ac.jp

Received March 07, 2015; Accepted March 26, 2015; Published March 28, 2015

Citation: Mori K, Ayano Y, Hamada Y, Hojima T, Tanaka R, et al. (2015) Role of 2,3-cis Structure of (-)-Epicatechin-3,5-O-digallate in Inhibition of HeLa S3 Cell Proliferation. Nat Prod Chem Res 3: 172. doi:10.4172/2329-6836.1000172

Copyright: (c) 2015 Mori K, et al. This is an open-access article distributed under the terms of the Creative Commons Attribution License, which permits unrestricted use, distribution, and reproduction in any medium, provided the original author and source are credited. 


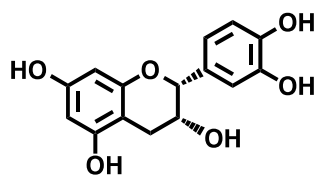

1

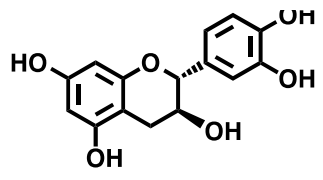

2
Figure 1: Structure of (-)-epicatechin (1) and (+)-catechin (2)

(DMSO) and stored at $-25^{\circ} \mathrm{C}$. HPLC purification was conducted on an Ascentis column (SUPELCO ${ }^{\circ}$ analytical; Sigma Aldrich Co. USA; 250 $\times 21.5 \mathrm{~mm} ; 5 \mu \mathrm{m}$ ) using $0.05 \% \mathrm{HCOOH}$ in $\mathrm{CH}_{3} \mathrm{CN}$ as solvent $\mathrm{A}$ and $0.05 \% \mathrm{HCOOH}$ and $10 \% \mathrm{CH}_{3} \mathrm{CN}$ in $\mathrm{H}_{2} \mathrm{O}$ as solvent $\mathrm{B}$. A linear gradient of $20 \%-100 \%$ solvent $\mathrm{A}$ in $\mathrm{B}$ over $20 \mathrm{~min}$ (flow rate; $4.0 \mathrm{ml} / \mathrm{min}$ ) was used for elution.

\section{Synthesis}

3',4',7-Tri-O-TBS-(-)-epicatechin (9): To a solution of $5,7,3^{\prime}, 4^{\prime}$-tetra-O-TBS-(-)-epicatechin (7) $(440 \mathrm{mg} ; 0.59 \mathrm{mmol})$ in $\mathrm{CH}_{2} \mathrm{Cl}_{2}(25 \mathrm{ml})$; TFA $(280 \mu \mathrm{l} ; 2.01 \mathrm{mmol})$ was added dropwise at $0^{\circ} \mathrm{C}$ to RT. After stirring for $2 \mathrm{~h}$; the pale yellow reaction mixture was quenched with sat. $\mathrm{NaHCO}_{3}$. The aqueous solution was extracted with $\mathrm{CHCl}_{3}$ and the organic phase was washed with water and brine and then dried $\left(\mathrm{MgSO}_{4}\right)$. Filtration; concentration and silica-gel column purification (hexane/EtOAc; 9:1 to 2:1) afforded $400 \mathrm{mg}(0.63 \mathrm{mmol}$; $84 \%$ ) of 9 as an amorphous solid. $[\alpha]_{D}^{24}=-58.3$ (c $0.26 ; \mathrm{CHCl}_{3}$ ); ${ }^{1} \mathrm{H}-\mathrm{NMR}\left(400 \mathrm{MHz} ; \mathrm{CDCl}_{3}\right) 6.97(1 \mathrm{H} ; \mathrm{s}) ; 6.94(1 \mathrm{H} ; \mathrm{br} \mathrm{s}) ; 6.86(1 \mathrm{H}$; $\mathrm{d} ; J=8.3 \mathrm{~Hz}) ; 6.09(1 \mathrm{H} ; \mathrm{s}) ; 5.95(1 \mathrm{H} ; \mathrm{s}) ; 5.22(1 \mathrm{H} ; \mathrm{br}) ; 4.91(1 \mathrm{H} ; \mathrm{s})$; 4.25 (1H; br s); 2.91-2.82 (2H; m); 1.82 (1H; br); 0.990 (9H; s); 0.989 $(9 \mathrm{H} ; \mathrm{s}) ; 0.96(9 \mathrm{H} ; \mathrm{s}) ; 0.20-1.86(9 \mathrm{H} ; \mathrm{m}) ;{ }^{13} \mathrm{C}-\mathrm{NMR}\left(100 \mathrm{MHz} ; \mathrm{CDCl}_{3}\right)$ $155.5 ; 155.3 ; 155.0 ; 147.0 ; 146.8 ; 131.0 ; 121.1 ; 119.30 ; 119.28 ; 100.9$; $100.6 ; 99.7 ; 78.1 ; 66.2 ; 27.5 ; 25.93 ; 25.91 ; 25.6 ; 18.45 ; 17.43 ; 18.1 ;-4.092$; $-4.097 ;-4.11 ;-4.12 ;-4.43 ;-4.45$; ESIMS $(m / z) 633\left([\mathrm{M}+\mathrm{H}]^{+} ; 100\right) ; 655$ $\left([\mathrm{M}+\mathrm{Na}]^{+} ; 14\right)$;ESIHRMS: $\mathrm{m} / \mathrm{z}\left(\mathrm{M}^{+}+\mathrm{H}\right)$ Calculated for $\mathrm{C}_{33} \mathrm{H}_{57} \mathrm{O}_{6} \mathrm{Si}_{3}$; 633.3463 Found; 633.3458.

3', 4',7-Tri-O-TBS-(+)-catechin (10): To a solution of $5,7,3^{\prime}, 4^{\prime}$-tetra-O-TBDMS-(+)-catechin $(8)(107 \mathrm{mg} ; 0.14 \mathrm{mmol})$ in $\mathrm{CH}_{2} \mathrm{Cl}_{2}(50 \mathrm{ml})$ was added dropwise TFA $(19 \mu \mathrm{L} ; 0.17 \mathrm{mmol})$ at $0^{\circ} \mathrm{C}$. After stirring for $5 \mathrm{~h}$; the pale yellow reaction mixture was quenched with sat. $\mathrm{NaHCO}_{3}$. The aqueous solution was extracted with $\mathrm{CHCl}_{3}$ and the organic phase was washed with water and brine and dried $\left(\mathrm{Na}_{2} \mathrm{SO}_{4}\right)$. Filtration; concentration and silica-gel column purification (hexane/EtOAc; $10: 1$ to 2:1) afforded a $82 \mathrm{mg}(0.13 \mathrm{mmol}$; $90 \%)$ of $\mathbf{1 0}$ as an amorphous solid. $[\alpha]_{D}^{24}=+87.6$ (c 1.14; $\left.\mathrm{CHCl}_{3}\right) ;{ }^{1} \mathrm{H}-\mathrm{NMR}(500$ $\left.\mathrm{MHz} ; \mathrm{CDCl}_{3}\right) 6.93(1 \mathrm{H} ; \mathrm{br}) ; 6.89(2 \mathrm{H} ; \mathrm{br}) ; 6.15(1 \mathrm{H} ; \mathrm{d} ; J=2.5 \mathrm{~Hz}) ; 6.00$ $(1 \mathrm{H} ; \mathrm{d} ; J=2.5 \mathrm{~Hz}) ; 5.61(1 \mathrm{H} ; \mathrm{br} ; \mathrm{OH}) ; 4.73(1 \mathrm{H} ; \mathrm{d} ; J=7.0 \mathrm{~Hz}) ; 4.08$ $(1 \mathrm{H}$; ddd; $J=5.5 ; 7.0 ; 8.5 \mathrm{~Hz}) ; 2.96(1 \mathrm{H} ; \mathrm{dd} ; J=5.5 ; 16.0 \mathrm{~Hz}) ; 2.66(1 \mathrm{H}$; dd; $J=8.5 ; 16.0 \mathrm{~Hz}) ; 2.09$ (1H; br); $1.03(9 \mathrm{H} ; \mathrm{s}) ; 1.00(9 \mathrm{H} ; \mathrm{s}) ; 0.99(9 \mathrm{H}$; s); $0.25(3 \mathrm{H} ; \mathrm{s}) ; 0.24(3 \mathrm{H} ; \mathrm{s}) ; 0.22(6 \mathrm{H} ; \mathrm{s}) ; 0.21(3 \mathrm{H} ; \mathrm{s}) ; 0.20(3 \mathrm{H} ; \mathrm{s})$. ${ }^{13} \mathrm{C}-\mathrm{NMR}\left(125 \mathrm{MHz} ; \mathrm{CDCl}_{3}\right) 155.60 ; 155.58 ; 155.1 ; 147.5 ; 147.4 ; 131.1$; $121.5 ; 120.3 ; 120.0 ; 101.1 ; 100.85 ; 100.79 ; 81.3 ; 68.5 ; 26.9 ;$ FABMS $(\mathrm{m} / \mathrm{z})$ 634 (20); 633 ([M+H] $\left.]^{+} ; 43\right) ; 632$ (27); 368 (32); 367 (100); HRFABMS: $\mathrm{m} / \mathrm{z}$ Calculated for $\mathrm{C}_{33} \mathrm{H}_{57} \mathrm{O}_{6} \mathrm{Si}_{3} ; 633.3463$ Found; 633.3447 .

(-)-Epicatechin-3,5-di-O-(tri-O-benzyl)gallate (12): To a solution of 9 (1.18 g; $1.87 \mathrm{mmol})$ and (tri-O-benzyl)gallic acid (1.99 $\mathrm{g} ; 4.66 \mathrm{mmol}$ ) was added DCC (0.96 g; $4.66 \mathrm{mmol})$ and DMAP (22 $\mathrm{mg} ; 0.18 \mathrm{mmol})$ in $\mathrm{CH}_{2} \mathrm{Cl}_{2}(75 \mathrm{ml})$ at $0^{\circ} \mathrm{C}$. After stirring for 3 days; the reaction mixture was quenched with water. The aqueous solution was extracted with $\mathrm{CHCl}_{3}$ and the organic phase was washed with water and brine and then dried $\left(\mathrm{MgSO}_{4}\right)$. Filtration; concentration and silica gel column purification $\left(\mathrm{CHCl}_{3} / \mathrm{EtOAc}\right.$; 200:1 to 2:1 followed by hexane/EtOAc; 10:1 to 2:1) afforded crude 11 as an amorphous solid. A solution of crude $\mathbf{1 1}$ in THF $(20 \mathrm{ml})$ was added dropwise to TBAF ( $3.46 \mathrm{ml} ; 3.46 \mathrm{mmol} ; 1 \mathrm{M}$ solution in THF) in the presence of AcOH $(0.20 \mathrm{ml} ; 3.46 \mathrm{mmol})$ at $0^{\circ} \mathrm{C}$. Concentration and a short silicagel column (hexane/EtOAc; 7:1 to 1:5) afforded $413 \mathrm{mg}$ (0.37 mmol; 2 steps 18\%) of $\mathbf{1 2}$ as an amorphous solid. Data for 11: [a]24 $D=-45.9$ (c 0.13; $\left.\mathrm{CHCl}_{3}\right) ;{ }^{1} \mathrm{H}-\mathrm{NMR}\left(400 \mathrm{MHz} ; \mathrm{CDCl}_{3}\right) 7.50-7.21(34 \mathrm{H} ; \mathrm{m}) ; 6.87$ $(1 \mathrm{H} ; \mathrm{d} ; J=2.0 \mathrm{~Hz}) ; 6.85(1 \mathrm{H} ; \mathrm{dd} ; J=2.0 ; 8.2 \mathrm{~Hz}) ; 6.72(1 \mathrm{H} ; \mathrm{d} ; J=8.2$ $\mathrm{Hz}) ; 5.58(1 \mathrm{H} ; \mathrm{br} \mathrm{s}) ; 5.16(6 \mathrm{H} ; \mathrm{s}) ; 5.12(1 \mathrm{H} ; \mathrm{s}) ; 5.16(2 \mathrm{H} ; \mathrm{s}) ; 5.58(4 \mathrm{H}$; s); $3.02(1 \mathrm{H} ; \mathrm{dd} ; J=15.1 \mathrm{~Hz}) ; 2.87(1 \mathrm{H} ; \mathrm{d} ; J=4.3 ; 15.1 \mathrm{~Hz}) ; 0.98(9 \mathrm{H}$; s); $0.94(9 \mathrm{H} ; \mathrm{s}) ; 0.91(9 \mathrm{H} ; \mathrm{s}) ; 0.23(6 \mathrm{H} ; \mathrm{s}) ; 0.15(3 \mathrm{H} ; \mathrm{s}) ; 0.14(3 \mathrm{H} ; \mathrm{s}) ; 0.09$ $(3 \mathrm{H} ; \mathrm{s}) ; 0.07$ (3H; s); ${ }^{13} \mathrm{C}-\mathrm{NMR}\left(100 \mathrm{MHz} ; \mathrm{CDCl}_{3}\right)$ 164.9; 163.8; 155.6; $155.2 ; 152.6 ; 152.3 ; 150.2 ; 146.74 ; 146.72 ; 143.1 ; 142.4 ; 137.4 ; 137.3$; $136.50 ; 136.46 ; 130.5 ; 128.51 ; 128.50 ; 128.4 ; 128.18 ; 128.16 ; 128.01$; $127.97 ; 127.95 ; 127.90 ; 127.52 ; 127.51 ; 127.50 ; 124.8 ; 123.9 ; 120.9$; $119.7 ; 119.2 ; 109.7 ; 109.0 ; 107.4 ; 105.9 ; 105.5 ; 75.2 ; 75.1 ; 71.3 ; 70.9 ; 68.0$; $60.3 ; 31.5 ; 25.9 ; 25.8 ; 25.6 ; 18.4 ; 18.3 ; 18.1 ;-4.1 ;-4.18 ;-4.26 ;-4.28$; $-4.4 ;-4.5$; ESIMS $(\mathrm{m} / \mathrm{z}) 1478\left([\mathrm{M}+\mathrm{H}]^{+} ; 8.7\right) ; 1501\left([\mathrm{M}+\mathrm{Na}]^{+} ; 64\right)$; ESIHRMS: $\mathrm{m} / \mathrm{z}\left(\mathrm{M}^{+}+\mathrm{H}\right)$ Calculated for $\mathrm{C}_{89} \mathrm{H}_{101} \mathrm{O}_{14} \mathrm{Si}_{3} ; 1477.6499$ Found 1477.6794; Data for 12: $[\alpha]_{D}^{24}=-18.4\left(c 0.22 ; \mathrm{CH}_{3} \mathrm{Cl}_{3}\right) ;{ }^{1} \mathrm{H}-\mathrm{NMR}(400$ $\mathrm{MHz}$; CD 3 OD) 7.49-7.19 (34H; m); $6.87(1 \mathrm{H} ; \mathrm{br} \mathrm{s}) ; 6.87-6.67(2 \mathrm{H} ; \mathrm{m})$; $6.43(1 \mathrm{H} ; \mathrm{d} ; J=2.4 \mathrm{~Hz}) ; 6.33(1 \mathrm{H} ; \mathrm{d} ; J=2.4 \mathrm{~Hz}) ; 5.49(1 \mathrm{H} ; \mathrm{dd} ; J=4.3$; $4.8 \mathrm{H}) ; 5.13-4.99(13 \mathrm{H} ; \mathrm{m}) ; 2.96(1 \mathrm{H} ; \mathrm{dd} J=4.8 ; 17.0 \mathrm{~Hz}) ; 2.76(1 \mathrm{H}$; dd; $J=4.3 ; 17.0 \mathrm{~Hz}) ;{ }^{13} \mathrm{C}-\mathrm{NMR}\left(100 \mathrm{MHz} ; \mathrm{CDCl}_{3}\right) 164.9 ; 163.8 ; 155.6$; $155.2 ; 152.6 ; 152.3 ; 150.2 ; 146.74 ; 146.72 ; 143.09 ; 142.41 ; 137.4 ; 137.3$; $136.50 ; 136.46 ; 130.5 ; 128.51 ; 128.50 ; 128.49 ; 128.45 ; 128.18 ; 128.16$; $128.01 ; 127.97 ; 127.95 ; 127.91 ; 127.52 ; 127.51 ; 127.50 ; 124.8 ; 123.9$; $120.9 ; 119.7 ; 119.2 ; 109.7 ; 109.0 ; 107.4 ; 105.9 ; 105.5 ; 75.2 ; 75.1 ; 71.3$; $70.9 ; 68.0 ; 60.3 ; 31.5 ; 25.87 ; 25.85 ; 25.83 ; 18.4 ; 18.3 ; 18.1 ;-4.1 ;-4.2$; $-4.25 ;-4.28 ;-4.45 ;-4.48$; ESIMS $(m / z) 1135\left([\mathrm{M}+\mathrm{H}]^{+} ; 16.9\right) ; 1157$ $\left([\mathrm{M}+\mathrm{Na}]^{+} ; 100\right)$; ESIHRMS: $\mathrm{m} / \mathrm{z}\left(\mathrm{M}^{+}+\mathrm{H}\right)$ Calculated. for $\mathrm{C}_{89} \mathrm{H}_{101} \mathrm{O}_{14} \mathrm{Si}_{3}$; 1157.3724 Found 1157.3722.

(-)-Epicatechin-3,5-di-O-gallate (3): A solution of 12 (413 mg; $0.37 \mathrm{mmol})$ in $\mathrm{THF} / \mathrm{MeOH} / \mathrm{H}_{2} \mathrm{O}(20: 1: 1 ; 11 \mathrm{ml})$ was hydrogenated over $20 \% \mathrm{Pd}(\mathrm{OH})_{2} / \mathrm{C}(2 \mathrm{mg})$ for $12 \mathrm{~h}$ at RT. Filtration and concentration afforded a pale brown solid; which was purified using HPLC purification to give $128 \mathrm{mg}$ of pure $3(0.21 \mathrm{mmol} ; 59 \%)$ as a pale brown powder [10-12]. $[\alpha]_{D}^{24}=-27.2(c 0.09 ; \mathrm{MeOH})\left\{\right.$ lit. ${ }^{10}[\alpha]_{D}^{23}=-5.4(c$ 2.17; MeOH)\}; ${ }^{1} \mathrm{H}-\mathrm{NMR}\left(400 \mathrm{MHz} ; \mathrm{CD}_{3} \mathrm{OD}\right) 7.17(2 \mathrm{H} ; \mathrm{s}) ; 6.93(2 \mathrm{H}$; s); $6.93(1 \mathrm{H} ; \mathrm{d} ; J=1.9 \mathrm{~Hz}) ; 6.81(1 \mathrm{H}$; dd; $J=1.9 ; 8.2 \mathrm{~Hz}) ; 6.69(1 \mathrm{H}$; $\mathrm{d} ; J=8.2 \mathrm{~Hz}) ; 6.36(1 \mathrm{H} ; \mathrm{d} ; J=2.4 \mathrm{~Hz}) ; 6.26(1 \mathrm{H} ; \mathrm{d} ; J=2.4 \mathrm{~Hz}) ; 5.50$ $(1 \mathrm{H}$; br s); $5.10(1 \mathrm{H} ; \mathrm{s}) ; 3.02(1 \mathrm{H} ; \mathrm{dd} ; J=4.4 ; 15.4 \mathrm{~Hz}) ; 2.77(1 \mathrm{H} ; \mathrm{d} ; J$ $=15.4 \mathrm{~Hz}) ;{ }^{13} \mathrm{C}-\mathrm{NMR}(100 \mathrm{MHz}$; CD $\mathrm{OD}) 174.4 ; 173.3 ; 165.1 ; 164.2$; $158.9 ; 153.6 ; 153.2 ; 153.0 ; 152.9 ; 147.5 ; 146.8 ; 137.9 ; 128.1 ; 127.1 ; 126.3$ $122.9 ; 122.0 ; 117.5 ; 117.1 ; 111.8 ; 110.7 ; 108.9 ; 85.7 ; 76.2 ; 34.1$; ESIMS $(\mathrm{m} / z) 595\left([\mathrm{M}+\mathrm{H}]^{+} ; 3\right) ; 617\left([\mathrm{M}+\mathrm{Na}]^{+} ; 17\right)$; ESIHRMS Calculated for $\mathrm{C}_{29} \mathrm{H}_{22} \mathrm{O}_{14} \mathrm{Na}$; 617.0902; Found; 617.0914.

(+)-Catechin-3;5-di-O-(tri-O-benzyl)gallate (14): To a solution of 10 (681 g; $1.07 \mathrm{mmol})$ and (tri-O-benzyl)gallic acid $(1.99 \mathrm{~g} ; 4.64$ mmol) was added DCC (962 mg; $4.66 \mathrm{mmol}$ ) and DMAP (23 mg; 0.19 $\mathrm{mmol})$ in $\mathrm{CH}_{2} \mathrm{Cl}_{2}(75 \mathrm{ml})$ at $0^{\circ} \mathrm{C}$. After stirring for 3 days; the reaction mixture was quenched with water. The aqueous solution was extracted with $\mathrm{CHCl}_{3}$ and the organic phase was washed with water and brine and then dried $\left(\mathrm{MgSO}_{4}\right)$. Filtration; concentration and silica-gel column purification $\left(\mathrm{CHCl}_{3} / \mathrm{EtOAc} ; 200: 1\right.$ and then hexane/EtOAc; 10:1 to 2:1) afforded crude $\mathbf{1 3}$ as an amorphous solid. A solution of crude $\mathbf{1 3}$ in 
Citation: Mori K, Ayano Y, Hamada Y, Hojima T, Tanaka R, et al. (2015) Role of 2,3-cis Structure of (-)-Epicatechin-3,5-O-digallate in Inhibition of HeLa S3 Cell Proliferation. Nat Prod Chem Res 3: 172. doi:10.4172/2329-6836.1000172

THF $(20 \mathrm{ml})$ was added dropwise to TBAF $(3.64 \mathrm{ml} ; 3.64 \mathrm{mmol} ; 1 \mathrm{M}$ solution in THF) in the presence of $\mathrm{AcOH}(0.20 \mathrm{ml} ; 3.64 \mathrm{mmol})$ at $0^{\circ} \mathrm{C}$. Concentration and a short silica gel column (hexane/EtOAc; 7:1 to 1:5) afforded $762 \mathrm{mg}(0.65 \mathrm{mmol} ; 2$ step $60 \%)$ of 14 as an amorphous solid. Data for 13: $[\alpha]_{D}^{24}-24.1\left(\right.$ c $\left.0.13 ; \mathrm{CHCl}_{3}\right) ;{ }^{1} \mathrm{H}-\mathrm{NMR}\left(400 \mathrm{MHz} ; \mathrm{CDCl}_{3}\right)$ 7.84-7.50 (34H; m); $7.26(1 \mathrm{H} ; \mathrm{d} ; J=1.7 \mathrm{~Hz}) ; 7.19-7.14(2 \mathrm{H} ; \mathrm{m}) ; 6.85$ $(1 \mathrm{H} ; \mathrm{d} ; J=2.3 \mathrm{~Hz}) ; 6.78(1 \mathrm{H} ; \mathrm{d} ; J=2.3 \mathrm{~Hz}) ; 5.81(1 \mathrm{H} ; \mathrm{ddd} ; J=4.9 ; 6.0$; $6.4 \mathrm{~Hz}) ; 5.57(1 \mathrm{H} ; \mathrm{d} ; J=6.0 \mathrm{~Hz}) ; 5.49-5.37(12 \mathrm{H} ; \mathrm{m}) ; 3.24(1 \mathrm{H} ; \mathrm{dd} ; J=$ $4.9 ; 16.6 \mathrm{~Hz}) ; 3.05(1 \mathrm{H} ; \mathrm{dd} ; J=6.4 ; 16.6 \mathrm{~Hz}) ; 1.34(9 \mathrm{H} ; \mathrm{s}) ; 1.32(9 \mathrm{H} ; \mathrm{s})$; 1.29 (9H; s); 0.59 (6H; s); $0.53(3 \mathrm{H} ; \mathrm{s}) ; 0.52(3 \mathrm{H} ; \mathrm{s}) ; 0.49(3 \mathrm{H} ; \mathrm{s}) ; 0.47$ $(3 \mathrm{H} ; \mathrm{s}) ;{ }^{13} \mathrm{C}-\mathrm{NMR}\left(100 \mathrm{MHz} ; \mathrm{CDCl}_{3}\right) 165.0 ; 163.7 ; 155.3 ; 155.0 ; 152.6$; $152.3 ; 149.9 ; 147.1 ; 146.9 ; 143.0 ; 142.4 ; 137.3 ; 137.2 ; 136.5 ; 136.4 ; 130.8$; $128.44 ; 128.73 ; 128.41 ; 128.40 ; 128.12 ; 128.09 ; 127.94 ; 127.91 ; 127.89$; $127.85 ; 127.5 ; 127.4 ; 124.7 ; 123.9 ; 121.1 ; 119.6 ; 118.8 ; 109.5 ; 108.9$ $107.3 ; 105.9 ; 105.6 ; 75.1 ; 75.0 ; 71.1 ; 70.9 ; 69.3 ; 34.8 ; 25.83 ; 25.81 ; 25.5$; $18.4 ; 18.3 ; 18.1 ;-4.32 ;-4.49 ;-4.50$; ESIMS $(m / z) 1477.7\left([\mathrm{M}+\mathrm{H}]^{+}\right.$; 12); $1499.6\left([\mathrm{M}+\mathrm{Na}]^{+} ; 81\right)$; ESIHRMS Calculated for $\mathrm{C}_{89} \mathrm{H}_{100} \mathrm{O}_{14} \mathrm{Si}_{3} \mathrm{Na}$; 1499.6313; Found; 1499.6318; Data for 14: $[\alpha]_{D}^{24}=+40.8($ c 0.42 ; $\left.\mathrm{CHCl}_{3}\right){ }^{11} \mathrm{H}-\mathrm{NMR}(400 \mathrm{MHz}$; CD $\mathrm{OD}) 7.50-7.17(34 \mathrm{H} ; \mathrm{m}) ; 6.96(1 \mathrm{H}$; d; $J=1.6 \mathrm{~Hz}) ; 6.81(1 \mathrm{H} ; \mathrm{d} ; J=8.2 \mathrm{~Hz}) ; 6.72(1 \mathrm{H} ; \mathrm{dd} ; J=1.6 ; 8.2 \mathrm{~Hz})$; $6.49(1 \mathrm{H} ; \mathrm{d} ; J=2.3 \mathrm{~Hz}) ; 6.23(1 \mathrm{H} ; \mathrm{d} ; J=2.3 \mathrm{~Hz}) ; 5.37-5.35(1 \mathrm{H} ; \mathrm{m})$; $5.30(1 \mathrm{H} ; \mathrm{d} ; J=3.7 \mathrm{~Hz}) ; 5.13-5.03(12 \mathrm{H} ; \mathrm{m}) ; 2.69(1 \mathrm{H} ; \mathrm{br} \mathrm{d} ; J=14.8$ $\mathrm{Hz}) ; 2.63(1 \mathrm{H}$; br d; $J=14.8 \mathrm{~Hz}) ;{ }^{13} \mathrm{C}-\mathrm{NMR}\left(100 \mathrm{MHz} ; \mathrm{CDCl}_{3}\right) 166.2$; $165.4 ; 155.6 ; 155.1 ; 152.7 ; 152.4 ; 149.4 ; 144.5 ; 143.8 ; 142.6 ; 137.2 ; 137.0$; $136.5 ; 136.2 ; 129.8 ; 128.53$ (Cx3); $128.5 ; 128.22 ; 128.20 ; 128.11 ; 128.08$; $128.01 ; 127.55$ (Cx2); $127.54(\mathrm{Cx} 2) ; 124.6 ; 122.7 ; 118.8 ; 115.2 ; 112.1$; $110.0 ; 109.2 ; 105.1 ; 103.0 ; 101.8 ; 77.8 ; 75.2 ; 75.1 ; 71.4 ; 71.1 ; 69.0 ; 21.5$; ESIMS $(m / z) 1135\left([\mathrm{M}+\mathrm{H}]^{+} ; 7.8\right) ; 1157\left([\mathrm{M}+\mathrm{Na}]^{+} ; 100\right)$; ESIHRMS Calculated for $\mathrm{C}_{71} \mathrm{H}_{59} \mathrm{O}_{14} ; 1135.3905$; Found; 1135.3899 .

(+)-Catechin-3,5-di-O-gallate (4): A solution of 14 (0.74 g; 0.66 $\mathrm{mmol})$ in $\mathrm{THF} / \mathrm{MeOH} / \mathrm{H}_{2} \mathrm{O}(20: 1: 1 ; 11 \mathrm{ml})$ was hydrogenated over $20 \%$ $\mathrm{Pd}(\mathrm{OH})_{2} / \mathrm{C}(2 \mathrm{mg})$ for $12 \mathrm{~h}$ at RT. Filtration and concentration afforded a pale brown solid; which was purified using HPLC purification to give $193 \mathrm{mg}$ of pure $4(0.32 \mathrm{mmol} ; 50 \%)$ as a pale brown powder [13]. $[\alpha]_{D}^{24}$ $=+16.8\left(\mathrm{c} 0.18 ; \mathrm{CHCl}_{3}\right) ;\left\{\right.$ lit. $^{13}[\alpha] 20 \mathrm{D}=+2.84($ c $\left.0.5 ; \mathrm{MeOH})\right\} ;{ }^{1} \mathrm{H}-\mathrm{NMR}$ $\left(400 \mathrm{MHz}\right.$; $\left.\mathrm{CD}_{3} \mathrm{OD}\right) 7.16(2 \mathrm{H} ; \mathrm{s}) ; 7.00(2 \mathrm{H} ; \mathrm{s}) ; 6.83(1 \mathrm{H} ; \mathrm{d} ; J=1.5 \mathrm{~Hz})$; $6.74(1 \mathrm{H} ; \mathrm{d} ; J=8.2 \mathrm{~Hz}) ; 6.72(1 \mathrm{H} ; \mathrm{dd} ; J=1.5 ; 8.2 \mathrm{~Hz}) ; 6.36(1 \mathrm{H} ; \mathrm{d} ; J=$ $2.4 \mathrm{~Hz}) ; 6.27(1 \mathrm{H} ; \mathrm{d} ; J=2.4 \mathrm{~Hz}) ; 5.38(1 \mathrm{H}$; ddd; $J=4.8 ; 5.3 ; 10.4 \mathrm{~Hz})$; $5.19(1 \mathrm{H} ; \mathrm{d} ; J=5.3 \mathrm{~Hz}) ; 2.75(1 \mathrm{H}$; dd; $J=4.8 ; 16.6 \mathrm{~Hz}) ; 2.66(1 \mathrm{H}$; dd; $J=5.44 ; 16.6 \mathrm{~Hz}) ;{ }^{13} \mathrm{C}-\mathrm{NMR}\left(100 \mathrm{MHz} ; \mathrm{CD}_{3} \mathrm{OD}\right) 174.4 ; 173.3 ; 165.3$; $163.4 ; 158.7 ; 153.6 ; 153.35 ; 153.31 ; 153.27 ; 147.6 ; 146.9 ; 138.0 ; 128.1$; $127.1 ; 125.9 ; 123.3 ; 121.1 ; 117.5 ; 117.1 ; 112.1 ; 110.6 ; 108.6 ; 86.3 ; 77.3$; 30.9; ESIMS $(m / z) 595\left([\mathrm{M}+\mathrm{H}]^{+} ; 2\right) ; 617\left([\mathrm{M}+\mathrm{Na}]^{+} ; 15\right)$; ESIHRMS Calculated for $\mathrm{C}_{29} \mathrm{H}_{23} \mathrm{O}_{14}$; 595.1082; Found; 595.1059.

3',4',7-Tri-O-TBS-(-)-epicatechin-5-O-(tri-O-benzyl)gallate (15): To a solution of 9 (577 $\mathrm{mg} ; 0.91 \mathrm{mmol})$ and (tri-O-benzyl)gallic acid (1.02 g; $2.40 \mathrm{mmol})$ was added EDC (372 $\mathrm{mg} ; 2.40 \mathrm{mmol})$ and DMAP (30 mg; $0.25 \mathrm{mmol})$ in $\mathrm{CH}_{2} \mathrm{Cl}_{2}(75 \mathrm{ml})$ at $0^{\circ} \mathrm{C}$. After stirring for $17 \mathrm{~h}$; the reaction mixture was quenched with water. The aqueous solution was extracted with $\mathrm{CHCl}_{3}$ and the organic phase was washed with water and brine then dried $\left(\mathrm{MgSO}_{4}\right)$. Filtration; concentration and silica gel column purification (hexane/EtOAc; 10:1 to 2:1) afforded 900 mg $(0.90 \mathrm{mmol} ; 93 \%)$ of $\mathbf{1 5}$ as an amorphous solid. $[\alpha]_{D}^{24}=+10.1(c$ $\left.0.40 ; \mathrm{CHCl}_{3}\right) ;{ }^{1} \mathrm{H}-\mathrm{NMR}\left(400 \mathrm{MHz} ; \mathrm{CDCl}_{3}\right) 7.52-7.26$ (17H; m); 6.98 $(1 \mathrm{H} ; \mathrm{d} ; J=1.8 \mathrm{~Hz}) ; 6.95(1 \mathrm{H} ; \mathrm{dd} ;=1.8 ; 8.2 \mathrm{~Hz}) ; 6.88(1 \mathrm{H} ; \mathrm{d} ; J=8.2 \mathrm{~Hz})$; $6.43(1 \mathrm{H} ; \mathrm{d} ; J=2.3 \mathrm{~Hz}) ; 6.37(1 \mathrm{H} ; \mathrm{d} ; J=2.3 \mathrm{~Hz}) ; 5.16(6 \mathrm{H} ; \mathrm{s}) ; 4.95(1 \mathrm{H}$; s); $4.18(1 \mathrm{H}$; br s); $2.85(1 \mathrm{H}$; dd; $J=4.0 ; 14.6 \mathrm{~Hz}) ; 2.77(1 \mathrm{H} ; \mathrm{d} ; J=14.6$ $\mathrm{Hz}) ; 1.77(1 \mathrm{H} ; \mathrm{br} \mathrm{s}) ; 1.00(18 \mathrm{H} ; \mathrm{s}) ; 0.99(9 \mathrm{H} ; \mathrm{s}) ; 0.23(6 \mathrm{H} ; \mathrm{s}) ; 0.217(6 \mathrm{H}$; s); $0.216(6 \mathrm{H} ; \mathrm{s}) ;{ }^{13} \mathrm{C}-\mathrm{NMR}\left(100 \mathrm{MHz} ; \mathrm{CDCl}_{3}\right) 163.8 ; 155.2 ; 155.0 ; 152.5$; $150.3 ; 146.9 ; 146.7 ; 142.9 ; 137.2 ; 136.4 ; 130.6 ; 128.43 ; 128.39 ; 128.08$;
$127.90 ; 127.86 ; 127.39 ; 124.0 ; 121.0 ; 119.14 ; 119.10 ; 109.5 ; 107.5 ; 105.9$; $105.5 ; 78.1 ; 75.0 ; 71.1 ; 65.8 ; 27.9 ; 25.83 ; 25.79 ; 25.5 ; 18.33 ; 18.29 ; 18.0$ $-4.20 ;-4.21 ;-4.24 ;-4.57 ;-4.59$; ESIMS $(m / z) 1055\left([\mathrm{M}+\mathrm{H}]^{+} ; 100\right)$; $1077\left([\mathrm{M}+\mathrm{Na}]^{+} ;\right.$45); ESIHRMS Calculated for $\mathrm{C}_{61} \mathrm{H}_{79} \mathrm{O}_{10} \mathrm{Si}_{3} ; 1055.4976$; Found; 1055.5010 .

3',4',7-Tri-O-TBS-(+)-catechin-5-O-(tri-O-benzyl)gallate (16): To a solution of $10(836 \mathrm{mg} ; 1.32 \mathrm{mmol})$ and (tri-O-benzyl)gallic acid (909 mg; $2.06 \mathrm{mmol}$ ) was added EDC (333 $\mathrm{mg} ; 2.14 \mathrm{mmol}$ ) and DMAP $(22 \mathrm{mg} ; 0.18 \mathrm{mmol})$ in $\mathrm{CH}_{2} \mathrm{Cl}_{2}(75 \mathrm{ml})$ at $0^{\circ} \mathrm{C}$. After stirring for $17 \mathrm{~h}$; the reaction mixture was quenched with water. The aqueous solution was extracted with $\mathrm{CHCl}_{3}$ and the organic phase was washed with water and brine and then dried $\left(\mathrm{MgSO}_{4}\right)$. Filtration; concentration and silicagel column purification (hexane/EtOAc; $10: 1$ to $2: 1$ ) afforded $1.13 \mathrm{~g}$ $(1.07 \mathrm{mmol} ; 62 \%)$ of $\mathbf{1 6}$ as an amorphous solid. $[\alpha]_{D}^{24}=+3.4(c 0.30$ $\left.\mathrm{CHCl}_{3}\right) ;{ }^{1} \mathrm{H}-\mathrm{NMR}\left(400 \mathrm{MHz} ; \mathrm{CDCl}_{3}\right)$ 7.53-7.26 (17H; m); $6.93(1 \mathrm{H} ; \mathrm{s})$; $6.88(2 \mathrm{H} ; \mathrm{s}) ; 6.43(1 \mathrm{H} ; \mathrm{s}) ; 6.39(1 \mathrm{H} ; \mathrm{s}) ; 5.17(2 \mathrm{H} ; \mathrm{s}) ; 5.15(4 \mathrm{H} ; \mathrm{s}) ; 4.71$ $(1 \mathrm{H} ; \mathrm{d} ; J=6.7 \mathrm{~Hz}) ; 4.01(1 \mathrm{H} ; \mathrm{ddd} ; J=5.4 ; 6.7 ; 8.5 \mathrm{~Hz}) ; 2.88(1 \mathrm{H} ; \mathrm{dd} ;$ $J=5.4 ; 16.1 \mathrm{~Hz}) ; 2.60(1 \mathrm{H} ; \mathrm{dd} ; J=8.5 ; 16.1 \mathrm{~Hz}) ; 1.87(1 \mathrm{H} ; \mathrm{br}) ; 1.02$ (9H; s); 1.00 (9H; s); 0.99 (9H; s); $0.23(12 \mathrm{H} ; \mathrm{s}) ; 0.21(6 \mathrm{H} ; \mathrm{s}) ;{ }^{13} \mathrm{C}-\mathrm{NMR}$ $\left(100 \mathrm{MHz} ; \mathrm{CDCl}_{3}\right) 163.9 ; 155.3 ; 155.1 ; 152.6 ; 150.5 ; 147.0 ; 146.9 ; 143.0$; $137.3 ; 136.5 ; 130.8 ; 128.54 ; 128.50 ; 128.2 ; 128.02 ; 127.98 ; 127.5 ; 124.1$ $121.1 ; 119.25 ; 119.22 ; 109.6 ; 107.6 ; 106.0 ; 105.7 ; 78.2 ; 75.2 ; 71.2 ; 66.0$; $28.0 ; 25.94 ; 25.91 ; 25.6 ; 18.5 ; 18.4 ; 18.1 ;-4.09 ;-4.10 ;-4.12 ;-4.45$; -4.46; ESIMS $(\mathrm{m} / \mathrm{z}) 1055\left([\mathrm{M}+\mathrm{H}]^{+} ; 55\right) ; 1077\left([\mathrm{M}+\mathrm{Na}]^{+} ; 51\right)$; ESIHRMS Calculated for $\mathrm{C}_{61} \mathrm{H}_{78} \mathrm{O}_{10} \mathrm{Si}$ Na; 1077.4795 ; Found; 1077.4761 .

(-)-Epicatechin-5-O-(tri-O-benzyl)gallate (17): A solution of $\mathbf{1 5}$ ( $900 \mathrm{mg} ; 0.85 \mathrm{mmol})$ in THF $(20 \mathrm{ml})$ was added dropwise to TBAF $(2.98$ $\mathrm{ml} ; 2.98 \mathrm{mmol}$; $1 \mathrm{M}$ solution in THF) in the presence of AcOH $(0.17$ $\mathrm{ml} ; 2.98 \mathrm{mmol})$ at $0^{\circ} \mathrm{C}$. Concentration and a short silica gel column purification (hexane/EtOAc; 7:1 to 1:5) afforded $350 \mathrm{mg}(0.49 \mathrm{mmol}$; $57 \%)$ of 17 as an amorphous solid. $[\alpha]_{D}^{24}=+13.8$ (c $\left.0.22 ; \mathrm{MeOH}\right)$; ${ }^{1} \mathrm{H}-\mathrm{NMR}$ (400 MHz; CD OD) 7.53-7.24 (17H; m); $6.97(1 \mathrm{H} ; \mathrm{br} \mathrm{s})$ 6.78-6.75 (2H; m); 6.32 (1H; br s); 6.26 (1H; br s); 5.18-5.09 (6H; m); $4.12(1 \mathrm{H} ; \mathrm{br} \mathrm{s}) ; 2.78(1 \mathrm{H} ; \mathrm{d} ; J=16.6 \mathrm{~Hz}) ; 2.58(1 \mathrm{H} ; \mathrm{dd} ; J=2.6 ; 16.6 \mathrm{~Hz})$; ${ }^{13} \mathrm{C}-\mathrm{NMR}(100 \mathrm{MHz}$; CD OD) $172.5 ; 164.9 ; 164.4 ; 160.9 ; 158.9 ; 152.9 ;$ $152.8 ; 150.9 ; 145.6 ; 145.0 ; 138.7 ; 136.6 ; 136.49 ; 136.48 ; 136.1 ; 136.02$; $136.00 ; 135.7 ; 126.3 ; 122.8 ; 122.2 ; 117.3 ; 112.5 ; 110.4 ; 109.0 ; 87.0 ; 83.1$; 79.1; 73.7; 36.5; ESIMS $(m / z) 713\left([\mathrm{M}+\mathrm{H}]^{+} ; 5\right) ; 735\left([\mathrm{M}+\mathrm{Na}]^{+} ; 46\right)$; ESIHRMS Calculated for $\mathrm{C}_{43} \mathrm{H}_{37} \mathrm{O}_{10} ; 713.2381$; Found; 713.2398.

(-)-Epicatechin-5-O-gallate (5): A THF/MeOH/ $\mathrm{H}_{2} \mathrm{O}(20: 1: 1 ; 11$ $\mathrm{ml}$ ) solution of 17 (350 $\mathrm{mg} ; 0.49 \mathrm{mmol})$ was hydrogenated over $20 \%$ $\mathrm{Pd}(\mathrm{OH})_{2} / \mathrm{C}(2 \mathrm{mg})$ for $12 \mathrm{~h}$ at RT [12]. Filtration and concentration afforded a pale brown solid; which was purified using HPLC purification to give $145 \mathrm{mg}$ of pure $5(0.25 \mathrm{mmol} ; 52 \%)$ as a pale brown powder. $[\alpha] 24 D=-126.3(c 0.12 ; \mathrm{MeOH}) ;\left\{\right.$ lit. $^{12}[\alpha]_{D}^{23}=+16.4$ (c 0.45; $\mathrm{MeOH})\} ;{ }^{1} \mathrm{H}-\mathrm{NMR}(400 \mathrm{MHz}$; CD $\mathrm{OD}) ; 7.20(2 \mathrm{H} ; \mathrm{s}) ; 6.97(1 \mathrm{H} ; \mathrm{d} ; J=$ $1.6 \mathrm{~Hz}) ; 6.79(1 \mathrm{H} ; \mathrm{dd} ; J=1.6 ; 8.2 \mathrm{~Hz}) ; 6.75(1 \mathrm{H} ; \mathrm{d} ; J=8.2 \mathrm{~Hz}) ; 6.31$ $(1 \mathrm{H} ; \mathrm{d} ; J=2.4 \mathrm{H}) ; 6.23(1 \mathrm{H} ; \mathrm{d} ; J=2.4 \mathrm{~Hz}) ; 5.01-4.80(1 \mathrm{H} ; \mathrm{m}) ; 4.16(1 \mathrm{H}$ br s); $2.85(1 \mathrm{H} ; \mathrm{dd} ; J=4.4 ; 16.6 \mathrm{~Hz}) ; 2.64(1 \mathrm{H}$; dd; $J=2.5 ; 16.6 \mathrm{~Hz})$; ${ }^{13} \mathrm{C}-\mathrm{NMR}$ (100 MHz; CD OD) $173.4 ; 164.8 ; 164.4 ; 159.1 ; 153.6 ; 152.9$; $152.8 ; 147.5 ; 138.7 ; 127.3 ; 126.3 ; 122.8 ; 122.2 ; 117.5 ; 112.7 ; 110.5 ; 108.8$; 87.0; 73.8; 36.5; ESIMS $(\mathrm{m} / z) 443\left([\mathrm{M}+\mathrm{H}]^{+} ; 16\right) ; 465\left([\mathrm{M}+\mathrm{Na}]^{+} ; 100\right)$; ESIHRMS Calculated for $\mathrm{C}_{22} \mathrm{H}_{18} \mathrm{O}_{10} \mathrm{Na}$; 465.0792; Found; 465.0770.

(+)-Catechin-5-O-(tri-O-benzyl)gallate (18): A solution of 16 $(1.00 \mathrm{~g} ; 0.95 \mathrm{mmol})$ in THF $(20 \mathrm{ml})$ was added dropwise to TBAF $(2.93$ $\mathrm{ml} ; 2.93 \mathrm{mmol}$; $1 \mathrm{M}$ solution in THF) in the presence of $\mathrm{AcOH}(0.17$ $\mathrm{ml} ; 2.93 \mathrm{mmol})$ at $0^{\circ} \mathrm{C}$. Concentration and a short silica gel column (hexane/EtOAc; 7:1 to 1:5) afforded $275 \mathrm{mg}(0.62 \mathrm{mmol}$; 65\%) of 18 as an amorphous solid. $[\alpha]_{D}^{24}=+26.9(c 0.15 ; \mathrm{MeOH}) ;{ }^{1} \mathrm{H}-\mathrm{NMR}(400$ $\mathrm{MHz}$; CD 3 OD) $7.50-7.19(15 \mathrm{H} ; \mathrm{m}) ; 6.83(1 \mathrm{H} ; \mathrm{d} ; J=2.0 \mathrm{~Hz}) ; 6.76(1 \mathrm{H}$ 
d; $J=8.1 \mathrm{~Hz}) ; 6.69(1 \mathrm{H} ; \mathrm{dd} ; J=2.0 ; 8.1 \mathrm{~Hz}) ; 6.28(2 \mathrm{H} ; \mathrm{s}) ; 5.10(4 \mathrm{H} ; \mathrm{s})$; $5.05(2 \mathrm{H} ; \mathrm{s}) ; 4.64(1 \mathrm{H} ; \mathrm{d} ; J=7.2 \mathrm{~Hz}) ; 3.97(1 \mathrm{H} ; \mathrm{ddd} ;=5.3 ; 7.2 ; 8.0$ $\mathrm{Hz}) ; 2.67(1 \mathrm{H} ; \mathrm{dd} ; J=5.3 ; 16.0 \mathrm{~Hz}) ; 2.23(1 \mathrm{H} ; \mathrm{dd} ; J=8.0 ; 16.0 \mathrm{~Hz})$; ${ }^{13} \mathrm{C}-\mathrm{NMR}(100 \mathrm{MHz}$; CD OD) $172.5 ; 165.0 ; 163.9 ; 160.9 ; 158.5 ; 153.3$; $150.9 ; 145.6 ; 145.0 ; 138.7 ; 135.7 ; 136.00 ; 136.02 ; 136.1 ; 136.47 ; 136.48$; $136.6 ; 132.4 ; 126.8 ; 123.1 ; 122.0 ; 117.3 ; 113.2 ; 110.4 ; 108.7 ; 89.9 ; 83.1$; 79.1; 75.0; 35.3; ESIMS $(\mathrm{m} / z) 735\left([\mathrm{M}+\mathrm{Na}]^{+} ; 57\right)$; ESIHRMS Calculated for $\mathrm{C}_{43} \mathrm{H}_{37} \mathrm{O}_{10} ; 713.2387$; Found; 713.2381 .

(+)-Catechin-5-O-gallate (6): A solution of 20 (50 mg; $0.07 \mathrm{mmol})$ in $\mathrm{THF} / \mathrm{MeOH} / \mathrm{H}_{2} \mathrm{O}(20: 1: 1 ; 11 \mathrm{ml})$ was hydrogenated over $20 \%$ $\mathrm{Pd}(\mathrm{OH})_{2} / \mathrm{C}(2 \mathrm{mg})$ for $12 \mathrm{~h}$ at RT. Filtration and concentration afforded a pale brown solid; which was purified using HPLC purification to give $21 \mathrm{mg}$ of pure $6(0.04 \mathrm{mmol} ; 67 \%)$ as a pale brown powder [14,15]. $[\alpha]_{D}^{24}=+26.9($ c $0.15 ; \mathrm{MeOH})\left\{\right.$ lit. ${ }^{14}[\alpha]_{D}^{20}=+2.7$ (c 3.0; acetone) $\}$ ${ }^{1} \mathrm{H}-\mathrm{NMR}\left(400 \mathrm{MHz} ; \mathrm{CD}_{3} \mathrm{OD}\right) 7.19(2 \mathrm{H} ; \mathrm{s}) ; 6.83(1 \mathrm{H} ; \mathrm{d} ; J=1.9 \mathrm{~Hz}) ; 6.76$ $(1 \mathrm{H} ; \mathrm{d} ; J=8.1 \mathrm{~Hz}) ; 6.71(1 \mathrm{H} ; \mathrm{dd} ; J=1.9 ; 8.1 \mathrm{~Hz}) ; 6.25(1 \mathrm{H} ; \mathrm{d} ; J=2.4 \mathrm{~Hz})$; $6.22(1 \mathrm{H} ; \mathrm{d} ; J=2.4 \mathrm{~Hz}) ; 4.64(1 \mathrm{H} ; \mathrm{d} ; J=7.4 \mathrm{~Hz}) ; 3.99(1 \mathrm{H} ; \mathrm{ddd} ; J=5.3$; $7.4 ; 8.2 \mathrm{~Hz}) ; 2.75(1 \mathrm{H} ; \mathrm{dd} ; J=5.3 ; 16.0 \mathrm{~Hz}) ; 2.49(1 \mathrm{H} ; \mathrm{dd} ; J=8.2 ; 16.0$ $\mathrm{Hz}) ;{ }^{13} \mathrm{C}-\mathrm{NMR}(100 \mathrm{MHz}$; CD OD) $173.4 ; 165.0 ; 163.9 ; 158.6 ; 153.6$; $153.3 ; 153.2 ; 147.5 ; 138.7 ; 127.2 ; 126.9 ; 123.0 ; 122.1 ; 117.5 ; 113.4 ; 110.4$; 108.5; 90.0; 75.1; 35.6; ESIMS $(\mathrm{m} / \mathrm{z}) 443\left([\mathrm{M}+\mathrm{H}]^{+} ; 13\right) ; 465\left([\mathrm{M}+\mathrm{Na}]^{+}\right.$; 94); ESIHRMS Calculated for $\mathrm{C}_{22} \mathrm{H}_{18} \mathrm{O}_{10} \mathrm{Na}$; 465.0792; Found; 465.0779.

Synthesis of the photoaffinity linker (21): NHS-LC-Biotin (Thermo Fisher Scientific Inc. IL; USA) (14 mg; $0.03 \mathrm{mmol}$ ) was added to a solution of photoaffinity amino linker [16] $(10 \mathrm{mg} ; 0.02 \mathrm{mmol})$ in $\mathrm{CH}_{2} \mathrm{Cl}_{2}(1 \mathrm{ml})$ at RT. After stirring for $2 \mathrm{~h}$; it was concentrated in vacuo. The residue was purified by silica-gel column chromatography $\left(\mathrm{CHCl}_{3} /\right.$ $\mathrm{MeOH}=10: 1)$ to give photoaffinity linker 21 (7.0 mg; $0.01 \mathrm{mmol} ; 42 \%)$ as a pale yellow oil. ${ }^{1} \mathrm{H}-\mathrm{NMR}\left(400 \mathrm{MHz} ; \mathrm{CDCl}_{3}\right)$ : $7.90(1 \mathrm{H} ; \mathrm{br}) ; 7.88$ $(2 \mathrm{H} ; \mathrm{d} ; J=8.5 \mathrm{~Hz}) ; 7.41(1 \mathrm{H} ; \mathrm{br}) ; 7.25(2 \mathrm{H} ; \mathrm{d} ; J=8.5 \mathrm{~Hz}) ; 6.55(1 \mathrm{H} ; \mathrm{br})$; $5.98(1 \mathrm{H} ; \mathrm{br}) ; 5.46(1 \mathrm{H} ; \mathrm{br}) ; 4.93(1 \mathrm{H} ; \mathrm{br}) ; 4.50(1 \mathrm{H} ; \mathrm{br}) ; 4.32(1 \mathrm{H} ; \mathrm{br})$; $3.64-3.53(15 \mathrm{H} ; \mathrm{m}) ; 3.53-3.51(2 \mathrm{H} ; \mathrm{m}) ; 3.42-3.40(2 \mathrm{H} ; \mathrm{m}) ; 3.24-3.23$ $(2 \mathrm{H} ; \mathrm{m}) ; 3.16-3.15(1 \mathrm{H} ; \mathrm{m}) ; 3.94-2.90(1 \mathrm{H} ; \mathrm{m}) ; 2.74-2.72(1 \mathrm{H} ; \mathrm{m})$; $2.19-2.16$ (4H; m); $1.68-1.64(11 \mathrm{H} ; \mathrm{m}) ; 1.50-1.48$ (4H; m); $1.35-1.34$ $(2 \mathrm{H} ; \mathrm{m}) ;{ }^{13} \mathrm{C}-\mathrm{NMR}\left(100 \mathrm{MHz} ; \mathrm{CDCl}_{3}\right)$ 173.2; $173.0 ; 166.3 ; 163.5 ; 135.6$; $131.9 ; 127.7 ; 126.33 ; 126.32 ; 77.1 ; 70.5 ; 70.38 ; 70.37 ; 70.36$ (Cx2); 70.34; $70.32 ; 70.0 ; 69.9 ; 69.8 ; 69.7 ; 61.7 ; 60.0 ; 55.4 ; 40.5 ; 39.9 ; 39.0 ; 36.0 ; 35.7$; $28.9 ; 27.9 ; 27.8 ; 26.3 ; 25.4 ; 25.0$; ESIMS $(\mathrm{m} / z) 832\left([\mathrm{M}+\mathrm{H}]^{+} ; 52\right) ; 854$ $\left([\mathrm{M}+\mathrm{Na}]^{+} ; 100\right)$; ESIHRMS Calculated for $\mathrm{C}_{37} \mathrm{H}_{57} \mathrm{~F}_{3} \mathrm{~N}_{7} \mathrm{O}_{9} \mathrm{~S} ; 832.3885$; Found; 832.3907

\section{DPPH radical scavenging activity}

DPPH radical scavenging activity was measured with following a general procedure [17]. A solution of DPPH radical in EtOH $(30 \mu \mathrm{M}$; $1.0 \mathrm{ml}$ ) was added to $1 \mu \mathrm{L}$ of each of the synthesized compounds in DMSO; and incubated at $30^{\circ} \mathrm{C}$ for $30 \mathrm{~min}$. The scavenging activity was estimated with a microplate reader (Filter Max F5 multi-mode microplate reader; Molecular Devices; Downingtown; PA; USA) to measure the $\mathrm{OD}$ at $515 \mathrm{~nm}$. Negative controls were prepared at the same time by adding $1 \mu \mathrm{L}$ of DMSO to $1.0 \mathrm{ml}$ of EtOH.

\section{Inhibitory activity of cell proliferation}

$10^{4}$ cells per well with $100 \mu \mathrm{L}$ of medium in a $37^{\circ} \mathrm{C}$ incubator equilibrated under an atmosphere of $5 \% \mathrm{CO}_{2}$ and $95 \%$ humidified air. D-MEM (Dulbecco's Modified Eagle's Medium; Gibco (Life technologies; Grand Island; NY; USA) supplemented with 5\% fetal bovine serum and $1 \%$ Pen-Strep; Invitrogen ${ }^{\mathrm{TM}}$ (Life technologies; Grand Island; NY; USA) was used. After $24 \mathrm{~h}$ of incubation; $1 \mu \mathrm{L}$ of the six synthesized compounds in DMSO were added and incubated for $48 \mathrm{~h}$. A well containing only a medium added with DMSO were used as negative controls and were prepared at the same time. After the medium was removed and the cells were washed with PBS; $90 \mu \mathrm{L}$ of the new medium and $10 \mu \mathrm{L}$ of the MTT solution (3-(4;5-dimethylthiazol2-yl)-2;5-diphenyltetrazolium bromide; $5 \mathrm{mg} / \mathrm{ml}$ ) were added to each well and incubated at $37^{\circ} \mathrm{C}$ for $2.5 \mathrm{~h}$. After incubation; the reaction medium was removed and $100 \mu \mathrm{L}$ of DMSO was added to each well and mixed thoroughly with a pipette. Viable cells were then assessed using a microplate reader (Filter Max F5 multi-mode microplate reader; Molecular Devices; Downingtown; PA; USA) to measure the $\mathrm{OD}$ at $570 \mathrm{~nm}$.

\section{Detection of non-specific binding between polyphenols and BSA}

A mixture of test sample $(3 ; \mathbf{4} ; \mathbf{5} ; \mathbf{6} ; \mathbf{1 9}$; or 20$)(100 \mu \mathrm{L} ; 10 \mathrm{mM}$ in $\mathrm{MeOH})$ and photoaffinity linker $21(5 \mu \mathrm{L} ; 10 \mathrm{mM}$ in $\mathrm{MeOH})$ was dried in vacuo and irradiated with 365 -nm-UV light; using a CL1000 L ultraviolet cross-linker (UVP Inc.; CA; USA). The irradiation energy amounted to $2.8 \mathrm{~J} \mathrm{~cm}^{-2}$. The mixture was dissolved in DMSO $(100 \mu \mathrm{L})$ and PBS $(400 \mu \mathrm{L})$. A mixture of the DMSO solution $(10 \mu \mathrm{L})$ and Streptavidin Agarose ( $40 \mu \mathrm{L}$; Novex; USA) was added to PBS (500 $\mu \mathrm{L} ; 0.1 \%$ Triton X-100) and incubated for $12 \mathrm{~h}$ at $4^{\circ} \mathrm{C}$. The beads were washed with PBS $(800 \mu \mathrm{L} ; 0.5 \%$ Triton X-100; 5 times) and PBS (800 $\mu \mathrm{L} ; 0.1 \%$ Triton X-100; once) and resuspended in PBS (500 $\mu \mathrm{L} ; 0.1 \%$ Triton X-100). To the beads solution; a solution of BSA in $\mathrm{H}_{2} \mathrm{O}(1$ $\mu \mathrm{L} ; 1 \mathrm{mM})$ was added and incubated for $12 \mathrm{~h}$ at $4^{\circ} \mathrm{C}$. After removal of the supernatant; the beads were washed with PBS $(800 \mu \mathrm{L} ; 0.1 \%$ Triton X-100; 4 times) and remained BSA on beads was separated by SDS-PAGE and followed silver staining of gel to give each BSA band. Determination of the band intensity was estimated by LI-COR; Image Studio Digits Ver 4.0.

\section{Results and Discussion}

\section{Synthesis}

Galloyl-modified flavan-3-ols can be isolated from various plants. Among them; (-)-epigallocatechin-3-O-gallate (EGCG) is the most well-known compound as it is a multi-functional small molecule extracted from green tea. In green tea; however; small amounts of various other galloyl-modified compounds are present as minor components; the health functions of which are unclear. Large amounts of each pure compound are required to elucidate their functions; however; the isolation and purification of these compounds for biological assays is difficult. Therefore; we have developed a simple; regioselective; and efficient synthesis of these compounds.

Figure 2 shows four galloyl-modified flavan-3-ols (3-6) synthesized using our regioselective deprotection approach. There have been no reports on the selective galloyl modification of the 5-position of flavan-3-ols; however; Mambu et al. reported the only semi-synthesis of $(+)$-catechin-5-O-gallate $(6)$ and its derivative. They reported the antiplasmodial and cytotoxic activities of this compound against human diploid embryonic lung cell line MRC-5 [15]. The isolation of 3-; 5-; and 3,5-O-digallate derivatives of (-)-epicatechin $(\mathbf{1})$ and $(+)$-catechin (2) and their biological activities have been described in several reports [10-14]. However; it is a rare case that (-)-epicatechin and (+)-catechin series compounds are present in the same plant; making SAR studies more difficult. Therefore; we synthesized galloyl analogs derived from $(-)$-epicatechin (1) and (+)-catechin (2); for elucidating their SAR.

Scheme 1 shows the synthesis of 3,5-O-digalloyl compounds 3 and 4 . The four phenolic hydroxyl groups of (-)-epicatechin (1) and $(+)$-catechin (2) were protected with TBS using a previously reported 
<smiles>O=C(Oc1cc(O)cc2c1C[C@@H](OC(=O)c1cc(O)c(O)c(O)c1)[C@H](c1ccc(O)c(O)c1)O2)c1cc(O)c(O)c(O)c1</smiles><smiles>O=C(Oc1cc(O)cc2c1C[C@@H](OC(=O)c1cc(O)c(O)c(O)c1)[C@H](c1ccc(O)c(O)c1)O2)c1cc(O)c(O)c(O)c1</smiles><smiles>O=C(Oc1cc(O)cc2c1C[C@H](O)[C@H](c1ccc(O)c(O)c1)O2)c1cc(O)c(O)c(O)c1</smiles><smiles>O=C(Oc1cc(O)cc2c1C[C@H](O)[C@H](c1ccc(O)c(O)c1)O2)c1cc(O)c(O)c(O)c1</smiles>

Figure 2: Structure of 5-O-galloyl flavan-3-ols.

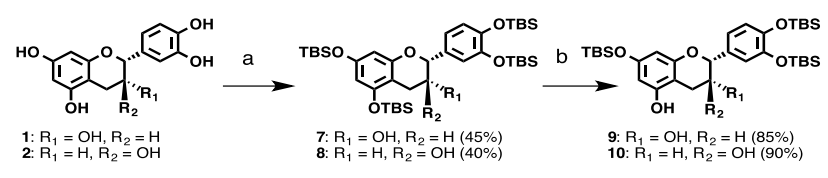

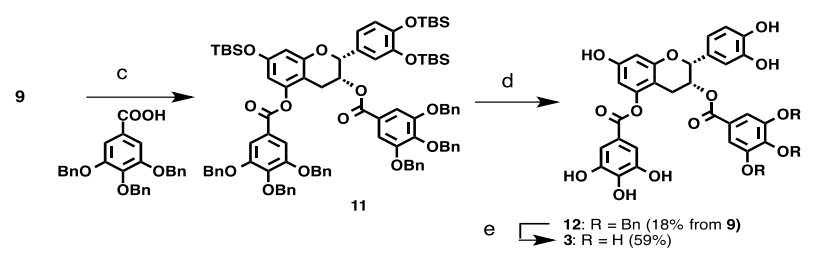

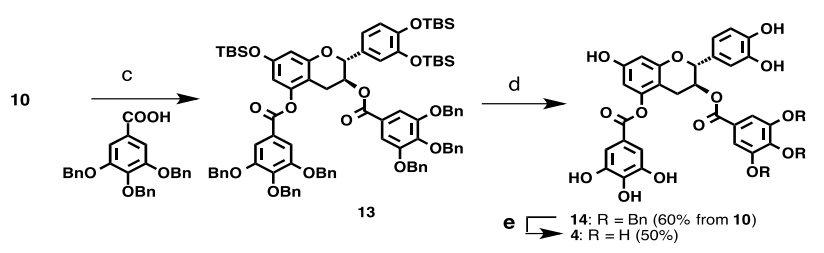

Scheme 1: Synthesis of 3,5-O-digalloyl compounds 3 and 4. Reagents and conditions: (a) imidazole, TBSCl, THF/DMF (1:1), (b) TFA $\mathrm{CH}_{2} \mathrm{Cl}_{2}$, (c) DCC, DMAP, $\mathrm{CH}_{2} \mathrm{Cl}_{2}$, (d) TBAF, AcOH, THF, (e) $\mathrm{Pd}(\mathrm{OH})_{2} / \mathrm{C}, \mathrm{H}_{2}$ $\mathrm{THF} / \mathrm{MeOH} / \mathrm{H}_{2} \mathrm{O}(20: 1: 1)$.

procedure [18]. Various examinations of the reactive properties of protected flavan-3-ols led us to discover that the 5-O-TBS groups of 7 and $\mathbf{8}$ could be regioselectively removed with TFA to give $\mathbf{9}$ and $\mathbf{1 0}$ in $85 \%$ and $90 \%$ yield; respectively. The structure of the $5-\mathrm{OH}$ products $\mathbf{9}$ and $\mathbf{1 0}$ were confirmed by the HMBC experiments. Esterification of dihydroxyl compounds $\mathbf{9}$ and $\mathbf{1 0}$ using benzyl-protected gallic acid and DCC proceeded smoothly to provide digalloyl compounds 11 and $\mathbf{1 3}$. The TBS groups of $\mathbf{1 1}$ and $\mathbf{1 3}$ were then removed with TBAF in the presence of $\mathrm{AcOH}$ to afford 12 and 14 in $18 \%$ and $60 \%$ yields (over 2 steps); respectively. Hydrogenation of the benzyl groups; which protect the phenolic hydroxyl groups on the galloyl moiety; gave $\mathbf{3}$ and $\mathbf{4}$ in $59 \%$ and $50 \%$ yields; respectively.

5-O-Galloyl derivatives 5 and $\mathbf{6}$ were synthesized as shown in Scheme 2. 5-Hydroxyl compounds $\mathbf{9}$ and $\mathbf{1 0}$ were esterified with benzyl protected gallic acid using EDC as a condensation reagent to give $\mathbf{1 5}$ and 16 in $88 \%$ and $66 \%$ yields; respectively.

Deprotection of the TBS groups gave 17 and 18 in 57\% and $65 \%$ yields; respectively. Subsequent hydrogenation afforded (-)-epicatechin-5-O-gallate (5) and (+)-catechin-5-O-gallate (6) in $52 \%$ and $67 \%$ yields; respectively. As the control compounds (-)-epicatechin-3-O-gallate (19) and (+)-catechin-3-O-gallate (20) were also synthesized (Figure 3) [3,4].

\section{DPPH radical scavenging activity}

Polyphenols are known as strong antioxidants and radical scavengers [17]. In previous papers [3-6]; we investigated the DPPH radical scavenging activity of synthesized procyanidin oligomers; and 3-O-galloyl dimers. In this study; we determined the $\mathrm{SC}_{50}$ values (the concentration at $50 \%$ scavenging activity) of compounds $3 ; 4$; $5 ; 6 ; 19$ and 20 to be $1.8 ; 2.6 ; 4.2 ; 2.3 ; 2.7$; and $5.2 \mu \mathrm{M}$; respectively. From these $\mathrm{SC}_{50}$ values and Figure 4; it appears that the synthesized galloyl-modified flavan-3-ols have significant radical scavenging activity; however; this is not affected by the number of galloyl moieties present on the molecule; contrary to our expectations. In addition; the 2;3-structure of flavan-3-ols appears to have minimal impact on the scavenging activity.

\section{Cervical epithelioid carcinoma cell line; HeLa S3; proliferation inhibitory activity}

The inhibitory activity of the synthetic galloyl-modified flavan3-ols against HeLa S3 cell proliferation is shown in Figure 5. While no inhibitory effect were observed for EGCG; 4-6; 19; or 20; (-)-epicatechin-3;5-O-digallate (3) inhibited proliferation of $\mathrm{HeLa}$ $\mathrm{S} 3$ cells quite strongly; based on our assay protocol $\left(\mathrm{IC}_{50}\right.$ value: 12.0 $\mu \mathrm{M} ; \mathrm{IC}_{50}$ : the concentration at $50 \%$ inhibitory activity). From the data for $(+)$-catechin-3;5-O-digallate (4); we can deduce that the stereochemistry at the 3 -position is critically important for this<smiles>O=C(O[C@H]1Cc2c(O)cc(O)cc2O[C@H]1c1ccc(O)c(O)c1)c1cc(O)c(O)c(O)c1</smiles><smiles>O=C(O[C@H]1Cc2c(O)cc(O)cc2O[C@H]1c1ccc(O)c(O)c1)c1cc(O)c(O)c(O)c1</smiles>

Figure 3: Structure of 3-O-galloyl flavan-3-ols.

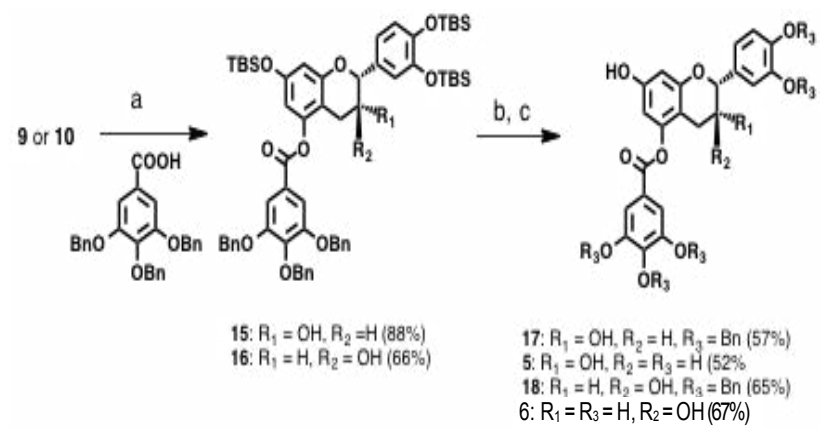

Scheme 2: Synthesis of 5-O-galloyl compounds 5 and 6. 


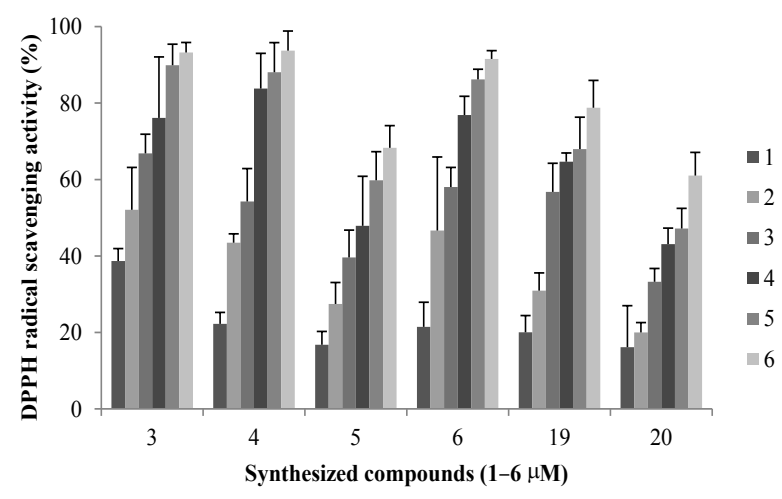

Figure 4: DPPH radical scavenging activity of the synthesized compounds Results were given as \% radical scavenging activity. Values represent mean $\pm S D(n=8)$

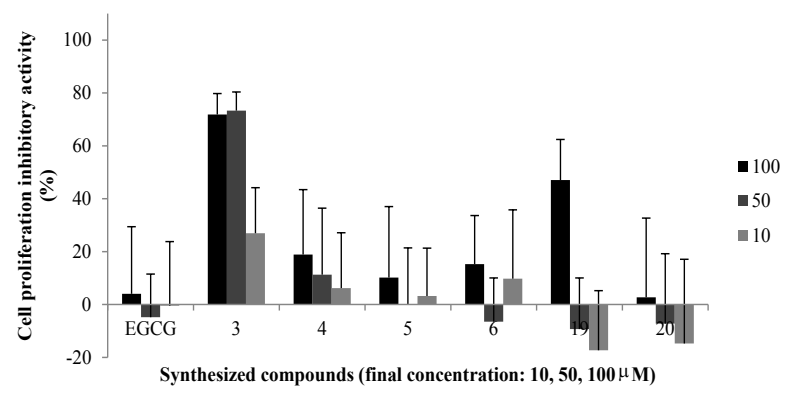

Figure 5: Inhibitory activity of synthetic galloyl-modified flavan-3-ols against HeLa S3 cell proliferation.

activity because the only difference between compounds 3 and 4 is the 2;3-structure. In addition; these results suggest that the biological activity of flavan-3-ols depends not only on the number of phenolic hydroxyl groups or galloyl moieties but also on other factors such as their structure.

HeLa S3 cells were incubated with a solution of each compound in DMSO for $48 \mathrm{~h}$. All error bars represent standard deviations of the mean $(\mathrm{n}>8)$.

\section{Non-specific binding assay of synthetic compounds with BSA}

Polyphenols show both specific and non-specific protein interactions [19]. Discoveries of EGCG specific receptors made a powerful impact on the field of polyphenol studies [20]. However various EGCG biological activities thought not to be due to specific interaction with its receptors have been reported. We have thought that the multifunctional properties of polyphenols are one of the most important features for functional food ingredients. But it often makes analysis of biological assay and elucidation of functionalities of polyphenols complicated. It is expected that non-specific bindings of polyphenol to protein especially affect biological assay such as cell proliferation inhibitory activity because of containing appreciable quantities of proteins. (-)-Epicatechin-3,5-O-digallate (3) inhibited proliferation of HeLa S3 cells quite strongly; but (+)-catechin-3,5-Odigallate (4) and other compounds were not. If the non-specific protein binding abilities of synthesized compounds are different; our assays may not evaluate correctly the activity of the compounds.
To elucidate the non-specific binding ability of polyphenols; we immobilized the synthesized polyphenols on beads in a "functional group-independent" manner using a modified photoaffinity linker $[15,21,22]$. We synthesized photoaffinity-biotin linker 21 (Figure 6A); which was then mixed with each of the compounds; dried; and irradiated with a $365 \mathrm{~nm}$ UV light. In this protocol; polyphenols are immobilized on the linker through a highly reactive carbene species generated from aryl diazirine upon UV irradiation. A biotinstreptavidin interaction could then occur between the polyphenolbound linkers and streptavidin sepharose beads. The interaction analysis between BSA; a protein present in large amounts in cell culture medium; and the polyphenol immobilized beads is shown in Figures $6 \mathrm{~B}$ and $6 \mathrm{C}$

The binding assay of the beads showed that the non-specific binding property of compound 3; the strongest cell proliferation inhibitor; was low. The non-active compounds $\mathbf{4}$; the stereoisomer of $\mathbf{3}$ also did not interact with BSA. This data suggests that non-specific binding to BSA didn't affect the activity difference between $\mathbf{3}$ and $\mathbf{4}$. In addition; (-)-epicatechin galloyl derivatives 5 and 19; the compounds that one of two galloyl moieties of $\mathbf{3}$ is removed; bound to BSA stronger than other compounds. These data also reveals that adsorption behavior of polyphenols to BSA is different depending on each structure. Further investigations to clarify the mechanisms of the inhibitory activity against HeLa S3 cell proliferation of $\mathbf{3}$ are now underway.

\section{Conclusion}

We synthesized galloyl-modified flavan-3-ols to elucidate their SAR with DPPH radical scavenging activity; HeLa S3 cells proliferation

(A)<smiles>O=C(CCCCC1SCC2NC(=O)NC21)NCCCCCC(=O)NCCOCCNC(=O)c1ccc(C(F)(F)F)cc1</smiles>

(B)

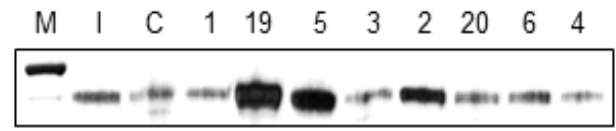

(C)

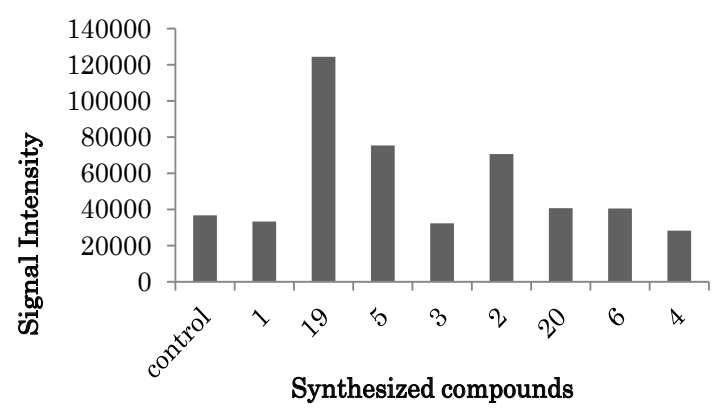

Figure 6: Nonspecific binding between polyphenols and BSA

(A) Structure of photoaffinity biotin linker (21)

(B) SDS-PAGE/silver-stain analysis of BSA binding to the beads on which each compound is immobilized. M: marker, I: input, C: control beads.

(C) Determination of band intensity by LI-COR, Image Studio Digits Ver 4.0 
Citation: Mori K, Ayano Y, Hamada Y, Hojima T, Tanaka R, et al. (2015) Role of 2,3-cis Structure of (-)-Epicatechin-3,5-O-digallate in Inhibition of HeLa S3 Cell Proliferation. Nat Prod Chem Res 3: 172. doi:10.4172/2329-6836.1000172

Page 7 of 7

inhibitory activity; and non-specific binding ability with BSA. Among the synthesized six compounds; (-)-epicatechin-3;5-O-digallate (3) showed the strongest inhibitory activity against HeLa S3 cell proliferation; but this activity did not have any relation to the DPPH radical scavenging activity or the non-specific protein binding property. Consequently; we determined that the 2,3-cis-structure of flavan-3-ols is critical for the inhibitory activity against HeLa S3 cell proliferation.

\section{Acknowledgment}

This work was supported by BRAIN: Program for Promotion of Basic and Applied Research for Innovations in Bio-oriented Industry (to A. Saito); technology research promotion program for agriculture; forestry; fisheries; food industry (to $A$ Saito); JSPS KAKENHI Grant Number 23780123 (Grant-in-Aid for Young Scientis (B) to A. Saito) and Grant Number 24590014 (Grants-in-Aid for Scientific Research (C) to N. Nakajima)

\section{References}

1. Harborne JB (1993) The Flavonoids: Advances in research from 1986 Chapman and Hall: London.

2. Harborne JB, Baxter H (1999) Handbook of Natural Flavonoids. The Handbook of Natural Flavonoids. John Wiley \& Sons, NY.

3. Saito M, Emoto A, Tanaka A, Doi Y, Shoji K, et al. (2004) Stereoselective synthesis of procyanidin B3-3-O-gallate and 3, 3"-di-O-gallate, and their abilities as antioxidant and DNA polymerase inhibitor. Tetrahedron 60: 12043-12049.

4. Saito A, Mizushina Y, Ikawa H, Yoshida H, Doi Y, et al. (2005) Systematic synthesis of galloyl-substituted procyanidin B1 and B2, and their ability of $\mathrm{DPPH}$ radical scavenging activity and inhibitory activity of DNA polymerases. Bioorg Med Chem 13: 2759-2771.

5. Sakuda H, Saito A, Mizushina Y, Ikawa H, Yoshida H, et al. (2006) Synthesis of Galloyl-substituted Procyanidin B4 Series, and Their DPPH Radical Scavenging Activity and DNA Polymerase Inhibitory Activity. Heterocycles 67: 175-188.

6. Saito A, Mizushina Y, Tanaka A, Nakajima N (2009) Versatile synthesis of epicatechin series procyanidin oligomers, and their antioxidant and DNA polymerase inhibitory activity. Tetrahedron 65: 7422-7428.

7. Cáceres-Mella Á, Peña-Neira A, Narváez JB, Carla JC, López-Solís R, et al (2013) Comparison of analytical methods for measuring proanthocyanidins in wines and their relationship with perceived astringency. Food Sci Tech 48 2558-2594.

8. Haslam E (1996) Natural polyphenols (vegetable tannins) as drugs: possible modes of action. J Nat Prod 59: 205-215.
9. Kidd PM (2009) Bioavailability and activity of phytosome complexes from botanical polyphenols: the silymarin, curcumin, green tea, and grape seed extracts. Altern Med Rev 14: 226-246.

10. Saijo R, Takeda Y (1999) HPLC Analysis of Catechins in Various Kinds of Green Teas Produced in Japan and Abroad. Nippon Shokuhin Kagaku Kogaku Kaishi 46: 138-147.

11. Hashimoto F, Nonaka G, Nishioka I (1989) Tannins and related compounds LXXVII. Novel chalcan-flavan dimers, assamicains $A, B$ and $C$, and a new flavan-3-ol and proanthocyanidins from the fresh leaves of Camellia sinensis $L$. var. assamica kitamura. Chem Pharm Bull 37: 77-85.

12. Kim HJ, Lee JY, Kim SM, Park DA, Jin C, et al. (2009) A new epicatechin gallate and calpain inhibitory activity from Orostachys japonicus. Fitoterapia 80: 73-76.

13. Ivanov SA, Nomura K, Malfanov IL, Sklyar IV, Ptitsyn LR (2011) Isolation of a novel catechin from Bergenia rhizomes that has pronounced lipase-inhibiting and antioxidative properties. Fitoterapia 82: 212-218.

14. Salem MM, Davidorf FH, Abdel-Rahman MH (2011) In vitro anti-uveal melanoma activity of phenolic compounds from the Egyptian medicinal plant Acacia nilotica. Fitoterapia 82: 1279-1284.

15. Ramanandraibe V, Grellier P, Martin MT, Deville A, Joyeau R, et al. (2008) Antiplasmodial phenolic compounds from Piptadenia pervillei. Planta Med 74: 417-421.

16. Saito A, Kawai K, Takayama H, Sudo T, Osada $H$ (2008) Improvement of photoaffinity SPR imaging platform and determination of the binding site of p62 SQSTM1 to p38 MAP kinase. Chem Asian J 3: 1607-1612.

17. Nanjo F, Goto K, Seto R, Suzuki M, Sakai M, et al. (1996) Scavenging effects of tea catechins and their derivatives on, 1-diphenyl-2-picrylhydrazyl radical. Free Radic Biol Med 21: 895-902.

18. Nakajima N, Horikawa K, Takekawa N, Hamada M, Kishimoto T (2012) Condensation of Catechin and Epicatechin Incorporating a TBS-Protecting Group. Heterocycles 84: 349-354.

19. Harbertson JF, Kilmister RL, Kelm MA, Downey MO (2014) Impact of condensed tannin size as individual and mixed polymers on bovine serum albumin precipitation. Food Chem 160: 16-21.

20. Tachibana H, Koga K, Fujimura Y, Yamada K (2004) A receptor for green tea polyphenol EGCG. Nat Struct Mol Biol 11: 380-381.

21. Kanoh N, Kumashiro S, Simizu S, Kondoh Y, Hatakeyama S, et al. (2003) Immobilization of natural products on glass slides by using a photoaffinity reaction and the detection of protein-small-molecule interactions. Angew Chem Int Ed Engl 42: 5584-5587.

22. Kanoh N, Honda K, Simizu S, Muroi M, Osada H (2005) Photo-cross-linked small-molecule affinity matrix for facilitating forward and reverse chemical genetics. Angew Chem Int Ed Engl 44: 3559-3562. 